\title{
DISCURSO DE POSSE COMO PROFESSOR TITULAR
}

\author{
NOMINATION ACCEPTANCE SPEECH AS A FULL PROFESSOR
}

Humberto Bergmann Ávila*

Exmo. Sr. Diretor, Professor Titular José Rogério Cruz e Tucci, em nome de quem cumprimento os demais Professores Titulares que compõem esta mesa, Alcides Jorge Costa e Luís Eduardo Schoueri, minhas senhoras e meus senhores.

Depois da saudação feita pelo Eminente Professor Titular Luis Eduardo Schoueri, de quem tenho a sincera honra de ser colega e que me acolheu, com a generosidade e o brilhantismo que lhe são característicos, nesta Faculdade, só me resta cumprir os requisitos de que se deve revestir uma boa exposição: falar alto para ser ouvido; claro para ser entendido; e pouco para ser aplaudido. Conquanto pretenda ser conciso, não serei breve. Como diz Pessoa, quando o assunto é importante e complexo, é preciso ser conciso, mas não breve, pois brevidade, em matéria complexa, é confusão.

Começo dizendo que estou comovido ao ver tantos amigos, do Brasil inteiro, aqui presentes, entre familiares, amigos, colegas e alunos. Posso imaginar o peso que muitos tiveram que carregar para estar aqui esta noite, afastando-se de compromissos tão importantes ou tendo que viajar de lugares tão distantes. Tranquilizo-me, porém, ao saber que são todos amigos, ao mesmo tempo em que me recordo daquele episódio, tantas vezes contado, a respeito da Batalha de Dunquerque. Dois soldados sofreram uma emboscada, tendo um deles ficado gravemente ferido. Este foi levado no colo pelo seu companheiro, em campo nevado e à noite, por dezesseis quilômetros, até o próximo vilarejo. Quando finalmente chegou ao destino, extenuado pelo inimaginável esforço físico que havia suportado para conduzir o colega ferido em seus braços, foi indagado por quem, espantado, o recebeu: como você conseguiu carregar este soldado pesado durante todo este tempo? Mas ele não pesa nada, disse o soldado, ele é meu irmão!

Esta pequena história, que lhes conto muito rapidamente, talvez explique este salão lotado de amigos vindos de todos os lugares do Brasil. A todos eles, só me cabe agradecer, de coração, não apenas pela presença, mas também pelo apoio incondicional que deles recebi por todos esses anos. Sem a sua ajuda, não teria ido tão longe. Afinal, como diz um antigo provérbio, se queres ir rápido, vá sozinho, mas se queres ir longe, vá acompanhado. Fico muito feliz por ter sido acompanhado e por estar ainda hoje sendo acompanhado por tantos amigos.

* $\quad$ Professor Titular do Departamento de Direito Econômico, Financeiro e Tributário da Faculdade de Direito da Universidade de São Paulo. 
Após estas considerações iniciais, pretendo falar sucessivamente sobre a Universidade de São Paulo, sobre a Cátedra de Direito Tributário, sobre a docência e, finalmente, sobre determinadas pessoas a quem devo um agradecimento especial.

A Universidade de São Paulo é a mais importante universidade da América Latina e uma das mais importantes do mundo. Por ela passaram 10 Presidentes da República, 45 Governadores de Estado, parlamentares, juristas, escritores, poetas. Ao longo da sua história, consolidou-se como um centro difusor de conhecimento para o Brasil e para o mundo, em suas mais variadas áreas de atuação. Eu, que estudei em universidades de muito prestígio e tradição, como as Universidades de Munique e de Harvard, posso assegurar que esta Universidade é uma grande universidade em termos de conhecimento e de tradição. Cabe a todos nós aprimorar este conhecimento e honrar esta tradição. Podemos fazê-lo de várias formas. Uma delas, muito especial e que envolve uma enorme responsabilidade, é ocupando uma Cátedra em uma de suas faculdades.

A Cátedra de Direito Tributário da Faculdade de Direito da Universidade de São Paulo, que passo a ocupar, é seguramente a cátedra mais tradicional do Brasil. Fundada em 1965, foi inicialmente ocupada pelo Eminente Professor Ruy Barbosa Nogueira, tendo depois passado pelas mãos dos Eminentes Professores Alcides Jorge Costa e Paulo de Barros Carvalho. Eu poderia falar de todos e de qualquer destes Professores, enaltecendo as suas características. Por angústia de tempo, homenagearei, e com muita honra, o Eminente Professor Alcides Jorge Costa.

Autor de obras importantes de Direito Tributário, entre livros e artigos, caracterizados pela sua concisão, objetividade e argúcia no trato de intrincados problemas teóricos e práticos, o Professor Alcides também contribuiu decisivamente para o aprimoramento da legislação em nosso país, já que é autor de diversas leis que produziram impactos significativos na tributação. No exercício destas atividades, ele revelou a sua singularidade: uma sabedoria prática invulgar. Como salienta Anthony Kronman, no seu livro "O Jurista Perdido" (The Lost Lawyer), o verdadeiro jurista é aquele sujeito dotado de sabedoria prática, isto é, de uma habilidade deliberativa capaz de permitir o adequado aconselhamento com relação a finalidades importantes para a sociedade. Tal sabedoria prática é mais do que uma simples especialidade ou habilidade técnica; é até mesmo um traço de caráter. Não tenho dúvida alguma de que o Professor Alcides é um desses poucos, pouquíssimos juristas brasileiros dotados desta sabedoria. A ela, ele conjuga outra virtude igualmente rara: a serenidade.

Como lembra Norberto Bobbio, na sua obra "Elogio da serenidade" (De Senectude), a serenidade é uma virtude fraca, não, porém, dos fracos. Ela significa o contrário da arrogância, que traduz a opinião exagerada que alguém possui de si próprio. Ela também contrasta com a insolência, que reflete a ostentação da arrogância e que se qualifica como defeito precisamente por ser ostentada. Afinal, quem ostenta caridade, 
aduz Bobbio, ressente-se de falta de caridade. Quem ostenta inteligência normalmente é um estúpido. A serenidade se diferencia da prepotência, na medida em que esta significa o abuso da potência, não só ostentada como exercida.

$\mathrm{O}$ aspecto mais importante que quero destacar, todavia, diz respeito às qualidades que o homem sereno possui na relação que mantém com os outros. $\mathrm{O}$ homem sereno deixa o outro ser o que é, ainda quando o outro é o arrogante, o insolente, o prepotente. $\mathrm{O}$ homem sereno não entra em contato com os outros para consentir, conflitar ou vencer. Convencido de que não há vencedores nem vencidos, ele aceita o outro, ouvindo-o e considerando as suas ideias. Fá-lo, porém, sem ser submisso, pois não renuncia à luta por medo ou fraqueza, antes procura compreender outras formas de examinar um mesmo problema. A serenidade, contudo, não equivale à humildade. Esta se opõe à vaidade. A serenidade contrasta, em vez disso, com a prepotência. $\mathrm{O}$ humilde não tem necessariamente esperança, ao passo que o sereno sempre espera por um mundo melhor, sem qualquer exigência de reciprocidade com relação a essa esperança.

Pois bem, o Professor Alcides é, sem sombra de dúvida, um homem sereno. Como Professor e como colega, sempre me deixou ser quem eu era, sem qualquer tipo de imposição de matrizes de pensamento ou de posições teóricas preconcebidas. Ao contrário, sempre com simplicidade e objetividade, aproximou-se de mim e de outros colegas com efetiva consideração e sem qualquer finalidade de sobrepor-se como pessoa ou de fazer prevalecer o seu ponto de vista. A verdade é que, a todos aqueles que querem seguir a sua verdadeira vocação, não resta senão a alternativa de seguir o seu próprio caminho. Como ressalta Pessoa, temos todos que nos contentar com sermos o que não podemos deixar de ser. Quero, pois, agradecer a todos os meus verdadeiros Mestres na pessoa do Professor Alcides, um verdadeiro professor, exemplo de sabedoria e de serenidade. Ocupar uma Cátedra ocupada por Vossa Excelência é motivo de elevada honra para mim.

A honra de ocupar esta Cátedra de Direito Tributário é naturalmente acompanhada de muita responsabilidade. Isso porque ao professor cabe o poder de influenciar os alunos. Esse poder cresce ainda mais quando os alunos são jovens. Como salienta Comênio, na sua obra "Didática Magna", os jovens são como vasos de barro, que conservam, até que se quebrem, o odor daquilo com que foram enchidos quando eram novos. Tal poder de influência não surge apenas por meio das aulas, mas também dos livros. Afinal, como lembra Caio Graco, os livros não mudam o mundo, quem muda o mundo são as pessoas; os livros só mudam as pessoas. Daí a responsabilidade da docência. Por meio dela, o professor deve permitir que os alunos sejam quem não podem deixar de ser. Ensinar é, de algum modo, ter esperança, esperança de que o ensino pode mudar as pessoas e elas o mundo.

Essa responsabilidade cresce em dimensão nos dias de hoje. Neste mundo em constante crise e mudança, a insegurança tomou conta das relações e também do próprio 
Direito. No entanto, se é verdade que as mudanças sociais, tecnológicas e jurídicas exigem novas soluções, também é verdade que os valores, que constituem a essência do Direito, continuam os mesmos. Os cidadãos continuam esperando e procurando por dignidade, liberdade, igualdade e segurança. Embora o objeto e as formas de manifestação desses valores possam ser diferentes, o fato é que esses valores continuam sendo os mesmos que fundaram a civilização moderna e o Direito moderno.

É precisamente neste ambiente que o Direito Tributário assume uma importância sem igual. Como a legislação possui várias fontes, nacionais, internacionais, comunitárias e até mesmo não formais, e essas fontes são modificadas com muita frequência, o apelo aos princípios fundamentais e à sua força centralizadora recobram o seu valor. Multitudo unum. Esse Direito Tributário, todavia, não pode mais ser examinado com a mesma matriz teórica. É urgente ampliar o exame do Direito Tributário para nele incluir não apenas regras e aspectos das suas hipóteses de incidência, mas também outros tipos de normas, como regras constitutivas e definitórias, princípios e postulados, e mesmo outros tipos de elementos, como fins, causas, elementos e fatos envolvidos na tributação ou pressupostos por ela. Mas, é preciso examinar o fenômeno tributário com precisão de linguagem e rigor conceitual, mas sem deixar de atentar para o caráter argumentativo do Direito e para a efetividade dos princípios e direitos fundamentais. O Direito Tributário, em suma, precisa ser examinado por meio de um novo método, orientado para a prática e fundado na teoria da argumentação, capaz de incorporar os avanços doutrinários conquistados pela Teoria do Direito nos últimos trinta anos.

Para isso, é preciso não apenas habilidade técnica. É preciso também uma grande dose de coragem. Coragem para romper com o imobilismo intelectual, para acabar com o argumento de autoridade, para fazer prevalecer o mérito acadêmico. Como diz Araújo Jorge, há pessoas que vão morrendo desde o nascer, que quando chega a morte, não há mais o que morrer. Daí a coragem exigida e esperada dos juristas na atualidade, notadamente no Brasil.

Por fim, queria fazer um agradecimento especial à minha família, em especial à minha mãe, que soube permitir que eu trilhasse o meu caminho do coração, à minha esposa, Ana Paula, e aos meus filhos, Georgia e André, que me apoiaram incondicionalmente e suportaram minhas longas ausências. Sem o seu apoio eu jamais teria conseguido conquistar os meus sonhos. Não curiosamente, o meu maior sonho sempre foi construir uma grande família, sonho que havia realizado antes deste que hoje realizo, talvez porque soubesse que sem ele jamais realizaria coisa alguma. A vocês, meus amores, o meu muito obrigado.

E, por último, um agradecimento a todos os presentes. Gostaria de nominálos, um a um, mas o tempo não o permite. Agradeço-lhes lembrando uma história contada por Gabriel García Marques. Em certa ocasião, ele sonhou com o seu autoexílio em 
Barcelona. Saudoso da casa e do mundo terminou por sonhar com a própria morte. No seu velório, todos beberam, comeram e se abraçaram como nos velhos e bons tempos. Em determinado momento, contudo, ele foi advertido de que não mais poderia acompanhá-los porque, afinal, ele estava morto. Quando acordou, tinha aprendido o que é verdadeiramente morrer: é não mais estar entre os amigos. A todos vocês que vieram de longe para estar aqui presentes, o meu efusivo agradecimento.

São Paulo, 20 de outubro de 2014. 


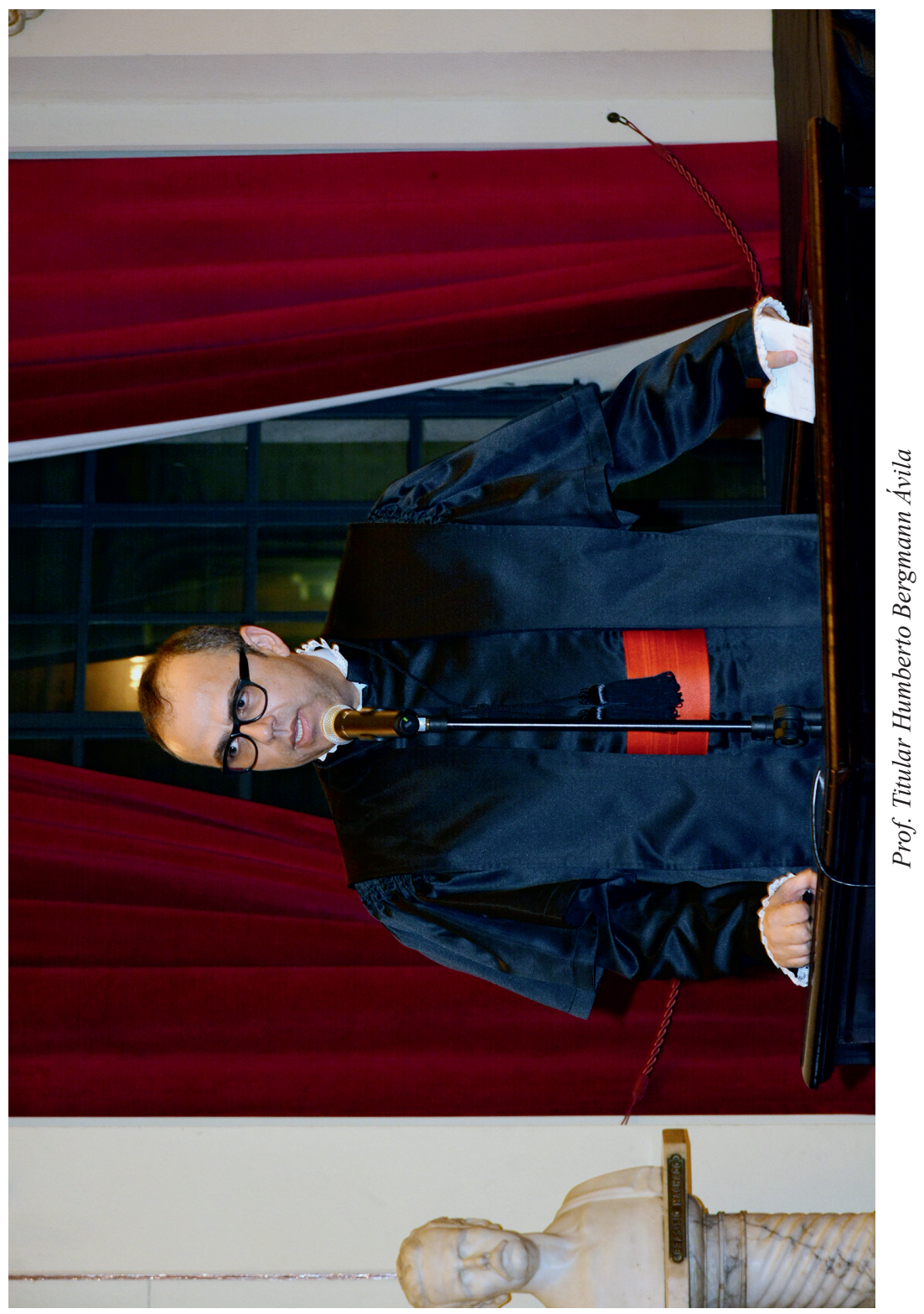

